\title{
The efficacy and feasibility of the beforehand-endoloop technique for colorectal endoscopic submucosal dissection
}

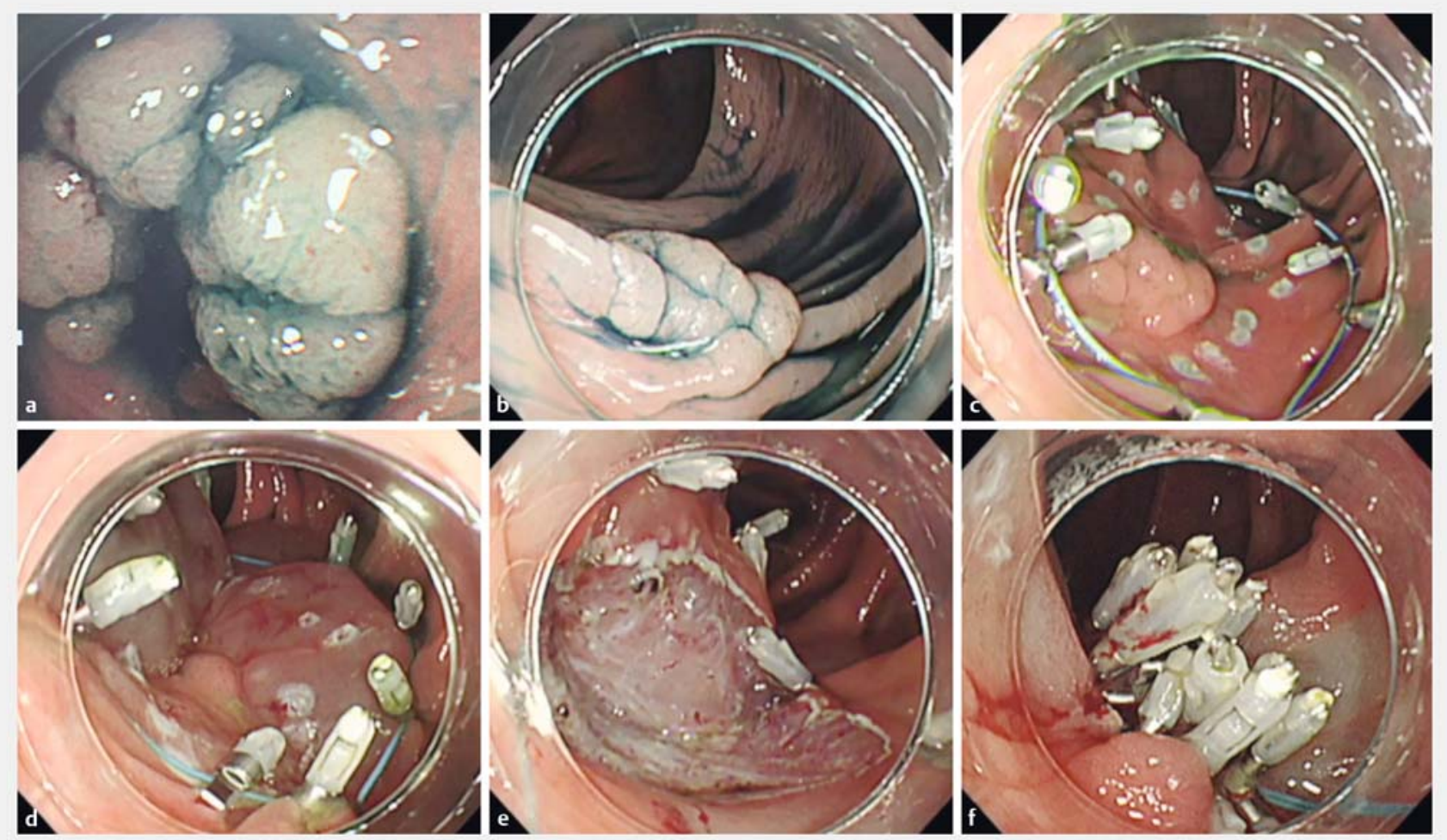

- Fig. 1 Endoscopic views showing: a a 15-mm adenoma in a diverticulum in the ascending colon; $\mathbf{b}$ an adenoma that recurred on the postendoscopic mucosal resection (EMR) scar; $\mathbf{c}$ the lesion at the start of the beforehand-endoloop technique; $\mathbf{d}$ inadequate submucosal lesion bulging after local injection owing to post-EMR scarring; e the mucosal defect after endoscopic submucosal dissection (ESD); $\mathbf{f}$ the completely closed mucosal defect after tightening the endoloop.

Intraoperative perforation of colorectal endoscopic submucosal dissection (ESD) often occurs. Therefore, techniques to close intraoperative perforations safely are important. Various methods for suturing mucosal defects to prevent postoperative bleeding and perforation have been reported $[1,2]$. To solve these problems, we report a technique we have developed, named the "beforehand-endoloop technique."

The patient had a 15-mm adenoma in a diverticulum in the ascending colon

( $\triangleright$ Fig. 1 a; $>$ Video 1) Endoscopic mucosal resection (EMR) was performed, but split adenomas remained in the diverticulum and a clip closure was performed on the mucosal defect. A recurrent adenoma was found on the EMR scar at endoscopy 6 months later ( $>$ Fig. 1 b). The patient agreed to undergo ESD to remove the recurrent adenoma.

Markings were placed on the normal mucous membrane around the lesion. An endoloop (MAJ254; Olympus) was placed over the lesion through the endoscope accessory channel and was fixed with a clip to the normal mucous membrane

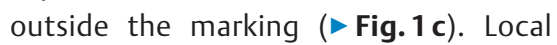
injections were performed around the lesion. The submucosal bulging due to the local injection was maintained using the same principle as in the preclipping method [3]; however, because of signifi- cant scarring, the submucosa under the lesion did not bulge ( $\triangleright$ Fig. $1 \mathbf{d}$ ).

The lesion was considered to carry a high risk of intraoperative perforation, but the submucosal bulge under the lesion, other than at the site of the fibrosis, persisted and complete resection using ESD was possible without intraoperative perforation. The mucosal defect after ESD ( $\triangleright$ Fig.1 e) was estimated to be approximately $30 \mathrm{~mm}$. Additional clips were added to fix the existing endoloop around the margins of the mucosal defect. The endoloop tail was then grasped using a hook device (HX-20Q-1; Olympus) and tightened to close the defect ( $\triangleright$ Fig. 1f; 


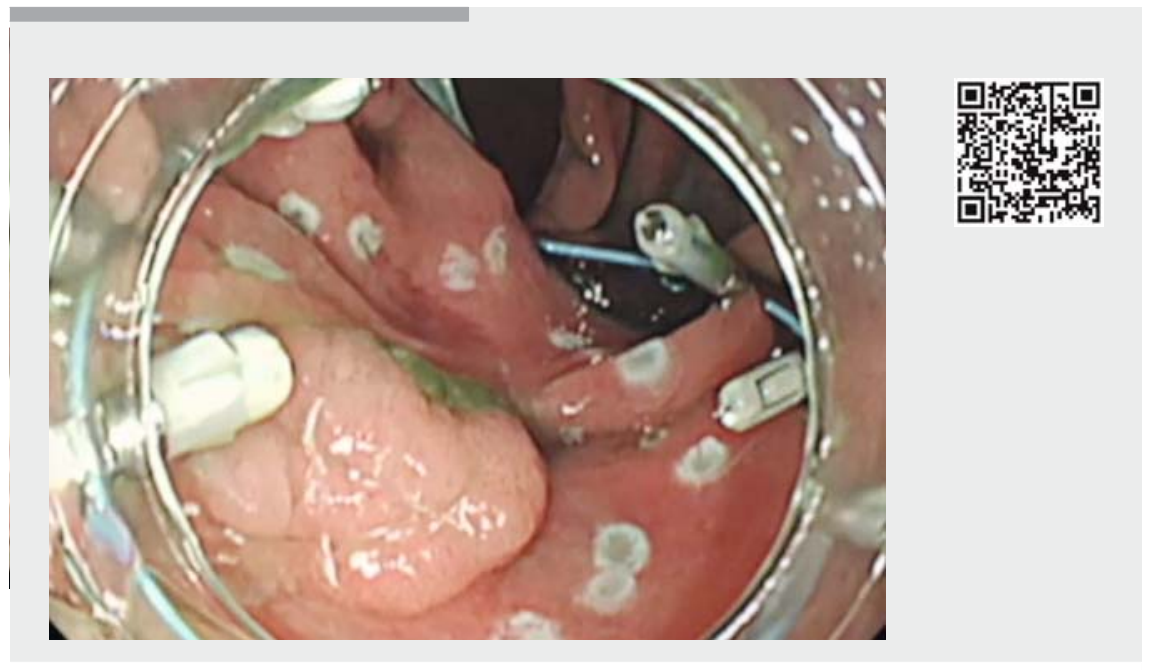

$\checkmark$ Video 1 Colorectal endoscopic submucosal dissection (ESD) performed using the beforehand-endoloop technique.

- Video 1). The patient recovered without any complications

Colorectal colonic ESD using the beforehand-endoloop technique is thus a useful and safe method of suturing mucosal defects.

Endoscopy_UCTN_Code_TTT_1AQ_2AD

Competing interests

None
[1] Akimoto T, Goto O, Sasaki M et al. "Holdand-drag" closure technique using repositionable clips for large mucosal defects after colonic endoscopic submucosal dissection. Endosc Int Open 2016; 4: E1068 -E1072

[2] Lua GW, Liu F. Closure of a large mucosal defect after endoscopic submucosal dissection using "pre-detached loop and clips" method with a single-channel gastroscope. Endoscopy 2015; 47 (Suppl. 01): E464E465

[3] Mori H, Kobara H, Nishiyama N et al. Safer endoscopic submucosal dissection for duodenal cancer with sufficient bulging by preclipping method. Gastrointest Endosc 2015; 82: $749-750$

\section{Bibliography}

DOI https://doi.org/10.1055/a-0596-6985

Published online: 13.4.2018

Endoscopy 2018; 50: 728-729

(c) Georg Thieme Verlag KG

Stuttgart · New York

ISSN 0013-726X

Tatsuma Nomura ${ }^{1}$, Shinya Sugimoto², Takaaki Morikawa ${ }^{1}$, Noriyuki Horiki ${ }^{3}$

1 Department of Gastroenterology, Kinan Hospital, Minamimuro, Mie, Japan

2 Department of Gastroenterology, Ise Red Cross Hospital, Ise, Japan

3 Department of Endoscopy, Mie University School of Medicine Tsu, Mie, Japan

\section{Corresponding author}

Tatsuma Nomura, MD

Department of Gastroenterology, Kinan Hospital, 4750 Atawa, Mihama-cho, Minamimuro-gun, Mie 519-5293, Japan Fax: +815-9792-3357 m06076tn@icloud.com 